\title{
The Impact of Pharmacist Care in a Shared Medical Appointment Model for the Management of Type 2 Diabetes in a Micronesian Population
}

\author{
Candace Tan ${ }^{1,2}$, Deborah T. Juarez ${ }^{1,2}$, Stacy Haumea ${ }^{3}$, and Charlotte Grimm ${ }^{3}$ \\ ${ }^{1}$ University of Hawaii at Hilo \\ ${ }^{2}$ The Daniel K. Inouye College of Pharmacy \\ ${ }^{3}$ Bay Clinic Inc.
}

\begin{abstract}
More than 25 million people have diabetes in the United States and its complications make it a leading cause of death. Pacific Islanders, specifically Micronesians, experience even higher rates of diabetes, and pharmacist care for these individuals may improve health outcomes. Objective: To better address health disparities in this population, a health center serving Hawaii Island added clinical pharmacy services into their shared medical appointment program for diabetes management. Methods: Standard care $(n=21)$ consisted of weekly education sessions for patients provided by a multi-disciplinary team, after which patients had one-on-one appointments with a primary care provider if they met threshold clinical criteria. The intervention group $(n=36)$ received the same services, plus a medication management service provided by a pharmacist during the one-on-one appointments. Results: There was no statistically significant difference between the pharmacist care and standard care groups on clinical measures including glycosylated hemoglobin, low density lipoprotein and blood pressure at the end of the eighteenmonth intervention period. Conclusion: Pacific Islanders face unique health care challenges including low socioeconomic status, language barriers and differences in cultural perceptions of health care. The value of clinical pharmacy has been well-documented in the literature but further study of the role and impact of these services is warranted for high-risk populations.
\end{abstract}

(c) 2014 Californian Journal of Health Promotion. All rights reserved.

Keywords: Clinical pharmacy services, multidisciplinary care, diabetes care, Pacific Islanders, Micronesians, shared medical appointment

\section{Introduction}

More than 25 million people, or $8.3 \%$ of the United States population, have diabetes. Diabetic complications are the seventh leading cause of death in the United States (Centers for Disease Control and Prevention, 2011), and the fifth leading cause of death among Asian American and Pacific Islanders (AAPI) (Centers for Disease Control and Prevention, 2012). The limited information that is available regarding Pacific Islanders from Micronesia suggests that they suffer disproportionately from diabetes, partially due to their high rates of obesity (Curtis, 2004; Davis et al., 2004; Lee et al., 2007; Stark, Niederhauser, Camacho, \& Shirai, 2011). This high-risk subgroup has rarely been included in clinical studies despite the fact that they are the one of the fastest growing AAPI subpopulations (2010 Census).

\section{Shared Medical Appointments}

The epidemic rate of diabetes is prompting the medical community to face care gap challenges in ways that will maximize treatment efficiency and effectiveness, while containing costs. One approach that is being implemented is the Shared Medical Appointment (SMA) model (Bendex \& Bower, 2011). SMAs differ from the traditional medical appointment in that a multidisciplinary team consisting of a primary health care provider (e.g. physician, nurse practitioner, physician assistant) along with support staff including a pharmacist, nurse, medical assistant, and other facilitators (e.g., a social worker, a psychologist, a dietician, etc.) sees a group of 
patients at the same time in an extended appointment. There are several models for SMAs including the drop-in group medical appointment (DIGMA), physical shared medical appointment (PSMA) and cooperative health care clinics (CHCC). This study used the CHCC model, which consists of a group education and support session followed by an individual session with the primary care provider and support team (Bendix \& Brower, 2011; Weinger, 2003).

At a time when the country is grappling with the primary care shortage, seeing several patients together has the potential to improve access to care, decrease heath care costs and increase care efficiency. In addition, the support from other fellow SMA patients and educational components from group sessions may also improve patient adherence and outcomes (Bendix \& Brower, 2011; Edelman et al., 2010; Schmucker, 2006). These factors may be especially beneficial for bridging the health care gap for Micronesians through increasing shared social support and health literacy.

There is limited information regarding the efficacy of SMAs in diabetes care, and what information is available is inconsistent. Some studies have shown minimal impact on clinical outcomes such as glycosylated hemoglobin (A1c), cholesterol and blood pressure (Clancy, Huang, Okonofua, Yeager, \& Magruder, 2007; Edelman et al., 2010) while others have shown an improvement in glycemic control (Desouza, Rentschler, \& Haynatzki, 2010; Pringle et al., 1993; Trento et al., 2001), and increases in preventive procedures, screenings, and patient education (Wagner et al., 2001).

\section{Role of Pharmacists in Shared Medical Appointments}

The estimated rate of non-adherence to diabetes medications is between 36 to 93\% (Bailey \& Kodack, 2011; Nair, Miller, Park, Allen, Saseen \& Biddle, 2010; Rosenfield, Hunt, Plauschinat, \& Wong, 2008). Pharmacists may enhance the quality of care provided in a SMA setting through provision of patient education regarding medications, as well as the disease state itself, nutrition, exercise, adherence and other components of comprehensive diabetes care. Information on the role and impact of pharmacist involvement in SMAs is sparse, but available information is positive, with pharmacist care improving glycemic control, lipid levels and blood pressure for intervention groups (Cohen et al., 2011; Kirsh et al., 2007; Taveira et al, 2010; Taveira, Dooley, Cohen, Khatana, \& Wu, 2011).

The purpose of this retrospective study is to evaluate the impact of clinical pharmacist care as part of a multidisciplinary SMA model delivering diabetes care for Micronesians as compared to a control SMA model that did not include pharmacist care. We predicted that pharmacist care would enhance the quality of diabetes care in a team approach and subsequently improve diabetes clinical health indicators in our study population. Not only does this information increase awareness of the role of pharmacists in SMA models of care, but also demonstrates the potential impact of pharmacist care for high-risk populations such as Pacific Islanders.

\section{Methods}

\section{Study Design}

In response to the diabetes epidemic, Hilo Bay Clinic, Inc. (BCI) piloted two SMA diabetes groups in 2006, one consisting of Chuukese patients and one of Marshallese patients, each SMA with separate translators for the two languages. The program had open enrollment, regardless of level of diabetes control. At the end of the trial period, those enrolled showed significant improvements in measured health indicators such as A1c and blood pressure (unpublished).

In January 2011, a clinical pharmacist on faculty at the University of Hawaii, The Daniel K. Inouye College of Pharmacy joined the diabetes multidisciplinary care team. Based on random assignment, the pharmacist provided medication therapy management services to the Marshallese SMA diabetes group. This intervention was compared to the standard care group, consisting of the Chuukese SMA diabetes group who did not receive additional clinical pharmacy 
services. The multidisciplinary standard care team consisted of a nurse practitioner, diabetes educator, dietician and translator.

\section{Clinical Pharmacy Service Description}

Group Sessions. The SMA diabetes program involved weekly group sessions taught by a registered dietician, certified diabetes educator or a registered nurse at BCI. Ten American Diabetes Association education standard topics were covered in one to two hour sessions over a revolving six-week course. However, the program had open enrolment and the vast majority of patients continued to attend weekly SMA sessions and appointments even after completing the course. The intervention group also received education workshops conducted by the pharmacist and student pharmacist during the intervention period. Pharmacist-led sessions occurred every six weeks and included interactive presentations and education on diabetes pathophysiology and complications, medications, value of adherence and other components of comprehensive diabetes care. There was significant emphasis placed on topics such as refill education and appropriate medication use, with multiple sessions focusing on obtaining individual patients' pharmacy information and designing and translating patient-specific monthly refill instruction sheets and protocols. Based on prior and ongoing feedback, presentation topics and interactive workshops were tailored to cultural differences in care needs.

Individual Sessions. After each group session, SMA patients continued on to an individual appointment with the primary care team based on screening performed during the group session and/or patient choice. Abnormal weight, pointof-care glucose and blood pressure readings triggered a same-day referral to individual appointment, as well as any new diabetes care issues reported by the patient or ongoing diabetes related concerns requiring follow-up. There was no cap to the number of patients who were seen for same-day individual appointments. The primary care provider and the clinical pharmacist saw the patient during the individual sessions and treatment plans were developed together at the point of care.
The clinical pharmacist evaluated the patient and made medication therapy recommendations including initiation, discontinuation and dosetitration of diabetes, hypertension and dyslipidemia medications. In addition, the pharmacist provided diabetes education, including nutrition and exercise management, blood glucose monitoring and hypoglycemia care education, and medication and adherence counseling during the appointment. The pharmacist also resolved any insurance and formulary discrepancies, provided pillbox filling and education services and responded to refill requests from both patients and pharmacies.

\section{Patients}

All patients enrolled at any point in the BCI Diabetes Self-Management Education (DSME) program between January 2011 and June 2013 were included in the study. The Marshallese group had 39 enrollees but three individuals were not included in the analysis as they did not have a diagnosis of diabetes. The Chuukese group had 21 enrollees; all were included in the analysis. The majority of patients enrolled in the program received Medicaid benefits and had an annual income of less than $\$ 20,000$. Additionally, most of the patients were nonEnglish speaking and communication was provided by translator services. Data on adherence rates to the program were not collected for this study, however it was noted by the SMA team that participants oftentimes had poor follow-up rates.

\section{Outcomes}

The primary outcomes, all components of comprehensive diabetes care, included the clinical health indicators of A1c, low-density lipoprotein cholesterol (LDL-C), high-density lipoprotein cholesterol (HDL-C), triglycerides (TG), total cholesterol (TC), body mass index (BMI) and blood pressure (both systolic and diastolic) (American Diabetes Association, 2014). These indicators, if available, were collected at baseline and quarterly every three months, over a period of 18 months. Baseline information was collected for the fourth quarter of 2010 prior to the integration of clinical pharmacy services for the intervention group. Data from the fourth quarter of 2010 was 
considered baseline for the control group. If no data was available during this period then the most recent data going backwards in time was considered baseline.

\section{Data Collection}

Patient data from SMA with pharmacist (intervention group, $\mathrm{n}=36$ ) and SMA without pharmacist (control group, $\mathrm{n}=21$ ) was collected retrospectively from patient charts and the electronic medical record (BCI transitioned from paper charts to electronic medical records during the data collection period).

\section{Statistical Analysis}

Observational retrospective analysis of diabetes health outcome indicators was conducted to evaluate the impact of a clinical pharmacist in the intervention arm as compared to the standard care arm. Fischer's exact test for categorical variables and t-tests for continuous variables were used to examine whether there were statistically significant differences in patient characteristics and clinical health indicators between the intervention and standard care groups at baseline.

To examine whether the intervention impacted changes in clinical health indicators for the invention group relative to the control group, we used a difference in difference approach utilizing a linear regression model (i.e., change in health indicator for the intervention group versus change in health indicator for the control group). In a second model, we adjusted for BMI which was the only patient characteristic that differed significantly between groups. The study was approved as exempt by the University of Hawaii Institutional Review Board (IRB).

\section{Results}

\section{Baseline Health Characteristics and Health Indicators}

Baseline patient health characteristics were similar between the two groups except for rates of obesity, which were significantly higher in the Chuukese group (standard care) at 80\% compared to $43 \%(p=0.006)$ in the Marshallese group (intervention) (Table 1). Furthermore, the Marshallese group trended towards a higher A1c (Table 2). Overall, 70\% had hypertension, 71\% had dyslipidemia and 13\% had cardiovascular disease. On average, A1c was 8.8\%, LDL cholesterol was $105.5 \mathrm{mg} / \mathrm{dL}$, HDL cholesterol was $37.5 \mathrm{mg} / \mathrm{dL}$ and triglycerides were 159 $\mathrm{mg} / \mathrm{dL}$.

Patients took an average of 4.4 medications, with no differences between the two groups in number of medications taken for diabetes, hypertension and dyslipidemia

\section{Table 1}

Baseline Health Characteristics for Intervention and Standard Care Arms

\begin{tabular}{lllll}
\hline & Overall $(\mathrm{n}=57)$ & Intervention $(\mathrm{n}=36)$ & Standard Care $(\mathrm{n}=21)$ & $\mathrm{p}$ \\
\hline Age [Mean (SD)] & $56.8(1.1)$ & $56.0(1.6)$ & $58.1(1.9)$ & 0.39 \\
Obese (BMI >30) (\%) & 57.1 & 42.9 & 81.0 & $0.006^{*}$ \\
Current smoker (\%) & 7.3 & 2.9 & 14.3 & 0.15 \\
Former smoker (\%) & 21.8 & 20.6 & 23.8 & 1.0 \\
Hypertension (\%) & 69.6 & 65.7 & 76.2 & 0.55 \\
Dyslipidemia (\%) & 71.4 & 80.0 & 57.1 & 0.13 \\
Coronary artery disease (\%) & 12.5 & 8.6 & 19.0 & 0.41 \\
Stroke (\%) & 5.4 & 8.6 & 0 & 0.28 \\
Condition count [Mean (SD)] & $4.4(0.3)$ & $4.6(0.3)$ & $4.0(0.6)$ & 0.34 \\
Number of medications (total) & $4.4(0.3)$ & $4.5(0.4)$ & $4.3(0.5)$ & 0.75 \\
$\quad$ Diabetes & $1.5(0.1)$ & $1.5(0.2)$ & $1.4(0.2)$ & 0.73 \\
Hypertension & $1.0(0.1)$ & $0.9(0.2)$ & $1.1(0.2)$ & 0.68 \\
$\quad$ Dyslipidemia & $0.8(0.1)$ & $0.9(0.1)$ & $0.7(0.1)$ & 0.24 \\
Diabetes medications (\%) & & & & 0.55 \\
$\quad$ Metformin & 69.1 & 65.7 & 75.0 & 0.55 \\
Sulfonylurea & 30.9 & 34.3 & 35.0 & 1.0 \\
$\quad$ DPP4 Inhibitor & 1.8 & 2.9 & 0.0 & 1.0 \\
$\quad$ Insulin & 30.9 & 31.4 & 30.0 &
\end{tabular}




\section{Table 2}

Clinical Health Indicators for Intervention and Standard Care Arms at Baseline

\begin{tabular}{|c|c|c|c|c|}
\hline & $\begin{array}{l}\text { Overall } \\
(n=57)\end{array}$ & $\begin{array}{l}\text { Interventi } \\
\text { on }(n=36)\end{array}$ & $\begin{array}{l}\text { Standard } \\
\text { Care } \\
(n=21)\end{array}$ & $\mathrm{p}$ \\
\hline $\begin{array}{l}\text { Weight [Mean } \\
\text { Kg (SD)] }\end{array}$ & $83.1(2.6)$ & 77.9 (3.2) & $92.0(3.5)$ & $0.007 *$ \\
\hline $\begin{array}{l}\text { Body Mass } \\
\text { Index (BMI) }\end{array}$ & $32.6(0.96)$ & $30.7(1.1)$ & $35.8(1.6)$ & $0.009 *$ \\
\hline A1c & $8.8(0.3)$ & $9.1(0.4)$ & $8.3(0.3)$ & 0.16 \\
\hline LDL & $105.5(.48)$ & $\begin{array}{l}105.2 \\
(6.0)\end{array}$ & $106.0(8.2)$ & 0.93 \\
\hline HDL & $37.5(0.9)$ & 37.8 (1.3) & $37.0(1.3)$ & 0.63 \\
\hline $\begin{array}{l}\text { Total } \\
\text { Cholesterol }\end{array}$ & $172.6(5.7)$ & $\begin{array}{l}175.7 \\
(7.6)\end{array}$ & $167.5(8.7)$ & 0.49 \\
\hline Triglycerides & $159.4(15.5)$ & $\begin{array}{l}173.5 \\
(22.7)\end{array}$ & $\begin{array}{l}135.9 \\
(16.3)\end{array}$ & 0.25 \\
\hline $\begin{array}{l}\text { Systolic } \\
\text { Blood } \\
\text { Pressure } \\
\text { Diastolic }\end{array}$ & $127.3(2.7)$ & $\begin{array}{l}126.8 \\
(3.7)\end{array}$ & $128.3(3.8)$ & 0.78 \\
\hline $\begin{array}{l}\text { Blood } \\
\text { Pressure }\end{array}$ & 76.4 (1.3) & $77.2(1.5)$ & 74.9 (2.7) & 0.40 \\
\hline
\end{tabular}

\section{Clinical Health Indicator Outcomes}

There were no statistically significant difference-indifference changes found between the intervention and standard care groups for any of the clinical health indicators including A1c, LDL and blood pressure at baseline and 18-month follow-up (Table 3), with and without adjustment, for BMI. The control group trended towards more weight loss than the intervention group, but the results did not reach statistical significance. There were fluctuations in A1c and LDL within the 18month follow-up period but there was no difference at the end of the study period.

\section{Discussion}

This study evaluated the potential impact of the addition of a clinical pharmacist into a SMA model of care for Micronesians with diabetes. There were no differences seen in clinical health indicators between the intervention arm receiving clinical pharmacist care and the standard care arm at the end of the 18-month study period, even when adjusted for BMI.

Table 3

Change in Health Indicator Measures for Intervention and Control Groups and Difference-In-Difference Estimate

\begin{tabular}{|c|c|c|c|c|c|c|}
\hline & & $\begin{array}{l}\text { Baseline } \\
\text { (Q4 2010) }\end{array}$ & $\begin{array}{l}\text { Follow-up } \\
\text { (Q1/Q2 } \\
\text { 2012) }\end{array}$ & $\begin{array}{l}\text { Change } \\
\text { (Follow-up } \\
\text { - Baseline) }\end{array}$ & $\begin{array}{l}\text { Difference- } \\
\text { in- } \\
\text { Difference }\end{array}$ & $\begin{array}{l}\text { p-value } \\
\text { adjusted } \\
\text { for BMI }\end{array}$ \\
\hline Body $\quad$ Mass & Intervention & 30.9 & 30.3 & -0.6 & 3.9 & NA \\
\hline Index (BMI) & Control & 35.8 & 31.3 & -4.5 & & \\
\hline \multirow{2}{*}{ HbA1C } & Intervention & 9.1 & 8.7 & -0.4 & -0.5 & 0.49 \\
\hline & Control & 8.3 & 8.5 & 0.2 & & \\
\hline \multirow{2}{*}{ LDL } & Intervention & 105.2 & 117.8 & 12.6 & 11.0 & 0.45 \\
\hline & Control & 106.1 & 107.6 & 1.5 & & \\
\hline \multirow{2}{*}{ HDL } & Intervention & 37.8 & 40.8 & 3.0 & 3.6 & 0.19 \\
\hline & Control & 37.0 & 36.3 & -0.7 & & \\
\hline \multirow{2}{*}{$\begin{array}{l}\text { Total } \\
\text { Cholesterol }\end{array}$} & Intervention & 175.7 & 186.5 & 10.8 & 14.2 & 0.35 \\
\hline & Control & 167.5 & 164.1 & -3.4 & & \\
\hline \multirow{2}{*}{ Triglycerides } & Intervention & 173.5 & 139.6 & -33.9 & 0.5 & 0.85 \\
\hline & Control & 135.9 & 101.5 & -34.4 & & \\
\hline Systolic Blood & Intervention & 126.8 & 129.1 & 2.3 & 0.9 & 0.76 \\
\hline Pressure & Control & 128.3 & 129.7 & 1.4 & & \\
\hline $\begin{array}{l}\text { Diastolic Blood } \\
\text { Pressure }\end{array}$ & Intervention & 77.2 & 77.2 & 0 & -0.3 & 0.90 \\
\hline
\end{tabular}

Diabetes is a growing epidemic nationally and Native Hawaiians and Pacific Islanders (NHPI) suffer disproportionately from the condition with it being two to four times more prevalent in NHPI than the general population (American Diabetes Association, n.d.; Mau, Sinclair, Saito, Baumhofer, \& Kaholokula, 2009; Moy, Sallis, \& David, 2010; Wergowske \& Blanchette, 2012). Due to their small population size NHPI are typically evaluated together in studies, although it is important to examine subpopulations since differences exist between rates of obesity, health status and healthcare access (Juarez, Samoa, Chung, \& Seto, 2010). For instance, we know that obesity rates are higher in Chuukese and Marshallese than other NHPI subpopulations (Davis et al., 2004; Lee et al., 2007; Stark, Niederhauser, Camacho, \& Shirai, 2011). Despite the Chuukese population growing by six times and Marshallese population growing by three times in the United States between 2000 and 2010 (2010 Census), little is known 
about the health and health care of this NHPI cohort with available information pointing to high levels of health disparities and poor health status (Moy, Sallis, \& David, 2010, US General Accounting Office, 2001, Wergowske \& Blanchette, 2012). SMAs are becoming a popular, nontraditional approach to managing high risk populations and multidisciplinary programs such as the one described which include clinical pharmacist care may improve health outcomes for these individuals.

While information regarding the role of pharmacist care in SMA models is scarce, the impact of clinical pharmacist care on diabetes outcomes has been welldocumented in the literature (Cranor, Bunting, \& Christensen, 2003; Fera, Bluml, \& Ellis, 2003; Machado, Bajcar, Guzz, \& Einarson, 2007). Recently, The Diabetes Initiative Program showed that collaboration between pharmacists and primary care physicians significantly decreased glycosylated hemoglobin (A1c) by $1.16 \%$ over a one-year period $(p<0.0001)$. Collaborative methods included several designs involving either independent prescribing by the pharmacist under collaborative practice agreement, dual physician-pharmacist appointments or independent pharmacist visits followed by consult with the physician (Farland, et al., 2013). In a health maintenance organization (HMO), inclusion of a pharmacist into primary care teams significantly reduced A1c by $2.6 \%$ as compared to control groups without pharmacist care over one_year $(\mathrm{p}<0.001)$. Projected long-term cardiovascular risk was also significantly decreased in the intervention arm receiving pharmacist care. In this model, uncontrolled diabetics with A1c $\geq 7 \%$ were referred by the primary care team to the pharmacist for more stringent follow-up; the pharmacist performed pharmacotherapy adjustments under collaborative practice agreement (Ip et al., 2013).

While our pilot program did not find a significant improvement in A1c between the pharmacist care and standard care groups, further study is still warranted to evaluate the role of pharmacist care in unique delivery models with high-risk patient population such as the one studied.

\section{Lessons Learned}

There were several notable unique challenges to providing quality care for this Micronesian cohort that may need to be taken into account when planning future pilot programs.

Transportation Barriers. Data for SMA program attendance was not collected, but it was observed that the program experienced significant rates of poor patient follow-up due to several reasons. Rural communities often experience unique health care barriers such as difficulty making follow-up appointments and classes due to challenges in obtaining transportation. This barrier to care was documented extensively in annual program evaluations completed by the patients in both study arms.

Health Literacy Barriers. While primary school enrollment rates in the Pacific Islands are high, access to secondary school is low, with data showing only $20 \%$ of children completing secondary education in one Pacific Island nation (Kidd, 2012). Even if children attend school, the quality of education may not be adequate to provide them an advantage in the labor market, and much less health literacy (Kidd, 2012). Our nonsignificant findings may indicate that the health education delivered may need to be modified to impact the study population more meaningfully.

Travel Barriers. Many Micronesians in the program took extended leave for months at a time to visit Micronesia. During these periods, they were often unable to obtain their chronic disease state medications, including those for diabetes.

Medication Refill Barriers. Medication refills were a particular challenge. Refill rates were not documented in the study, but significant amount of pharmacist time were spent educating on the value of refills as well as how to obtain a refill. All Micronesian patients are eligible for Medicaid in the United States. Even though they do not pay a medication co-payment, yearly changes to the formulary, which affect what medications are available, may have a significant impact on patient adherence in this population with poor health literacy. When medication changes were made to accommodate formularies, it was noted by the health care team that poor fill rates occurred. This may have been due to multiple reasons including unclear understanding of the medications, language barriers and transportation difficulties. A formal and structured approach to refill education may be warranted to enhance adherence in the future.

Study Design Barriers. The program may have limited its own efficacy due to its design. The large SMA group size increased wait times to see the primary care team after the initial education session. These wait times could be nearly three to four hours long in the intervention arm as compared to shorter wait times in the smaller standard care arm. The limiting factor was translator services since only one patient could be seen at a time, given the language barrier. While not 
documented, many patients who were unable or unwilling to wait for their one-on-one appointment left prior to being seen. Additionally, those who were seen individually had limited amount of time with the pharmacist for one-on-one education. In this population with low literacy, expanding individual appointment time by increasing translation services may be critical to improving health outcomes.

\section{Limitations and Future Directions}

We conclude that our lack of significant findings in this study may be due to multiple limitations including study design, program design and challenges to care in this unique population. Our study was limited by its retrospective nature and small sample size; future directions include prospective analysis of larger population cohorts, as well as controlling for potential confounding factors involved with differences in ethnicity and cultural backgrounds. Streamlining programs to decrease wait times may aid in improving adherence and attendance, evaluation of the program with consistent health care follow-up may alter results. Additionally, increasing access and care time spent with the pharmacist in medication and disease state counseling and education may enhance patient understanding and improve both adherence and involvement in their own health care. Finally, tailored interventions that address other unique health care challenges in these patient populations, such as language barriers, physical access to care and differences in cultural perception of health and health care are critical. Pharmacists involved in such programs may undergo training programs to enhance their cultural sensitivity and awareness as well.

As the nationwide diabetes epidemic grows, the medical community must find innovative and effective solutions to address patient care needs. These efforts may show that pharmacist-directed care, within SMA models, improves patient outcomes in underserved populations.

\section{Acknowledgements}

The authors would like to acknowledge Joanne Kamei, BSN, RN; Vita Angelov, RD; Craig Nutter, PharmD; Anthony Thai, PharmD; and Megan Venegas, PharmD for their contribution to the study.

\section{Disclosure Statement}

Stacy Haumea and Charlotte Grimm are employed by Bay Clinic Inc. at the time of this writing but the study was not funded or sponsored by the organization. No other authors reported any financial disclosures.

\section{References:}

American Diabetes Association. (n.d.). In my community: Hawaii. Retrieved on August 20, 2013 from: http://www.diabetes.org/in-my-community/local-offices/honolulu-Hawaii/.

American Diabetes Association. (2014). Standards of medical care in diabetes-2014. Diabetes Care, 37(S1), 14-80.

Bailey, C.J. \& Kodack, M. (2011). Patient adherence to medication requirements for therapy of type 2 diabetes. International Journal of Clinical Practice 65(3), 314-322.

Bendix, J. \& Brower, A. (February 2011). The benefits of sharing: Shared medical appointments can improve your patients' outcomes and your practice's efficiency. Medical Economics, 68-76.

Centers for Disease Control and Prevention. (2012). National Center for Health Statistics. Health, United States, 2011: With Special Feature on Socioeconomic Status and Health. Retrieved on August 20, 2013 from: http://www.cdc.gov/nchs/data/hus/hus11.pdf.

Centers for Disease Control and Prevention. (2011). National Diabetes Fact Sheet, 2011. Retrieved on August 20, 2013 from: http://www.cdc.gov/diabetes/pubs/pdf/ndfs_2011.pdf.

Cohen, L.B., Taveira, T.H., Khatana, S.A., Dooley, A.G., Pirraglia, P.A, \& Wu, W.C. (2011). Pharmacist-led shared medical appointments for multiple cardiovascular risk reduction in type 2 diabetes. The Diabetes Educator, 37(6), 801-812.

Clancy, D.E., Huang, P., Okonofua, E., Yeager, D., \& Magruder, K.M. (2007). Group visits: $\quad$ Promoting adherence to diabetes guidelines. Journal of General Internal Medicine, 22(5), 620-624.

Cranor, C.W., Bunting, B.A., \& Christensen, D.B. (2003). The Asheville Project: Long-term clinical and economic outcomes of a community pharmacy diabetes care program. Journal of American Pharmacists Association, 43(2), 173-184.

Curtis, M. The obesity epidemic in the Pacific Islands. (2004). Journal of Development and Social Transformation, 1, 37-42. 
Tan, C., Juarez, D.T., Haumea,S., Grimm, C. / Californian Journal of Health Promotion 2014, Volume 12, Issue 2, $13-21$.

Davis, J., Busch, J., Hammatt, Z., Novotny, R., Harrigan, R., Grandinetti, A., \& Easa, D. (2004). The relationship between ethnicity and obesity in Asian and Pacific Islander populations: A literature review. Ethnicity \& Disease, 14, 111-118.

Desouza, C.V., Rentschler, L., \& Haynatzki, G. (2010). The effect of group clinics in the control of diabetes. Primary Care Diabetes, 4(4), 251-254.

Edelman, D., Fredrickson, S.K., Melnyk, S.D., Coffman, C.J., Jeffreys, A.S., Dalta, $\quad$ S.,...Weingberger, M. (2010). Medical clinics versus usual care for patients with both diabetes and hypertension: A randomized trial. Annals of Internal Medicine, 152(11), 689- 696.

Farland, M.Z., Byrd, D.C., McFarland, M.S., Thomas, J., Franks, A.S., George, C.M.,...Suda, K.J. (2013). Pharmacist-physician collaboration for diabetes care: the diabetes initiative program. The Annals of Pharmacotherapy, 47, 781-789.

Fera, T., Bluml, B.M., Ellis, W.M. (2003). Diabetes Ten City Challenge: final economic and clinical results. Journal of American Pharmacy Association, 49(3), 383-391.

Ip, E.J., Shah, B.M., Yu, J., Chan, J., Nguyen, L.T., \&Bhatt, D.C. (2013). Enhancing diabetes care by adding a pharmacist to the primary care team. American Journal of Health-System Pharmacy, 70, 877-886.

Juarez, D.T., Samoa, R.A., Chung, R.S., \& Seto, T.B. (2010). Disparities in health, obesity and access to care among an insured populations of Asian and Pacific Islander Americans in Hawaii. Hawaii Medical Journal, 69, 42-46.

Kidd, S. (2012). Achieving education and health outcomes in Pacific Island communities - is there a role for social transfers? Retrieved on August 20, 2013 from: http://www.ausaid.gov.au/aidissues/foodsecurity/Documents/education-health-social- $\quad$ transfers.pdf.

Kirsh, S., Watts, S., Pascuzzi, K., O’Day, M.E., Davidson, D., Strauss, G.,...Aron, D.C. (2007). Shared medical appointments based on the chronic care model: A quality improvement project to address the challenges of patients with diabetes with high cardiovascular risk. Quality \& Safety in Health Care, 16, 349-353.

Lee, D.F., Lindshield, C.J., Kuribayashi, T., Kleinschmidt, C.K., Lee, E.K., \& Omori, J.S. (2007). Health problems of Micronesian patients at a student-run free homeless clinic. Pacific Health Dialog, 14, 254-262.

Mau, M.K., Sinclair, K., Saito, E.P., Baumhofer, K.N., \& Kaholokula, J.K. (2009). ～Cardiometabolic health disparities in Native Hawaiian and other Pacific Islanders. $\quad$ Epidemiologic Reviews, 31, 113-129.

Machado, M., Bajcar, J., Guzzo, G.C., \& Einarson, T.R. (2007). Sensitivity of patient outcomes to pharmacist interventions. Part I: systematic review and meta-analysis in diabetes management. Annals of Pharmacotherapy, 41(10), 1159-1582.

Moy, K.L., Sallis, J.F., \& David, K.J. (2010). Health indicators of Native Hawaiian and Pacific Islanders in the United States. Journal of Community Health, 35, 81-92.

Nair, K.V., Miller, K., Park, J., Allen, R.R., Saseen, J.J., \& Biddle, V. (2010). Prescription co-pay reduction program for diabetic employees. Population Health Management, 13(5), 235-245.

Pringle, M., Stewart-Evans, C., Coupland, C., Williams, I., Allison, S., \& Sterland, J. (1993). Influences on control in diabetes: Patient, doctor, practice or delivery of care? British Medical Journal, 306, 360-364.

Rosenfield, Y., Hunt, J.S., Plauschinat, C., \& Wong, K.S. (2008). Oral antidiabetic medication adherence and glycemic control in managed care. The American Journal of Managed Care 14(2), 71-75.

Schmucker, D. (2006). Group medical appointments: An introduction for health professionals. Sudbury, MA: Jones \& Bartlett.

Stark, M.J., Niederhauser, V.P., Camacho, J.M., \& Shirai, L. (2011). The prevalence of overweight and obesity in children at a Health Maintenance Organization in Hawai'i. Hawaii Medical Journal, 70, 27-31.

Taveira, T.H., Dooley, A.G., Cohen, L.B., Khatana, S.A., \& Wu, W.C. (2011). Pharmacist-led group medical appointments for the management of type 2 diabetes with comorbid depression in older adults. The Annals of Pharmacotherapy, 45, 1346-55.

Taveira, T.H., Friedman, P.D., Cohen, L.B., Dooley, A.G., Khatana, S.A., Pirraglia, P.A., \& Wu, W.C. (2010). Pharmacist-led group medical appointment model in type 2 diabetes. The Diabetes Educator, 36(1), 109-117. 
Trento, M., Passera, P., Tomalino, M., Bajardi, M., Pomero, F., Allione, A.,...Porta, M. (2001). Group visits improve metabolic control in type 2 diabetes: A 2-year follow-up. Diabetes Care, 24(6), 995-1000.

United States General Accounting Office (2001). Migration from Micronesian nations has had significant impact on Guam, Hawaii, and the Commonwealth of the Northern Mariana Islands. Washington, D.C.

Wagner, E.H., Grothaus, L.C., Sandhu, N., Galvin, M.S., McGregor, M., Artz, K., \& Coleman, E.A. (2001). Chronic care clinics for diabetes in primary care: A system-wide randomized trial. Diabetes Care, 24, 695-700.

Weinger, K. (2003). Group medical appointments in diabetes care: Is there a future? Diabetes Spectrum, 16, 104-107.

Wergowske, G., \& Blanchette, P.L. (2012). Health and health care of elders from Native Hawaiian and other Pacific Islander backgrounds. Retrieved on August 20, 2013 from http://www.stanford.edu/group/ethnoger/nativeHawaiian.html.

Author Information

*Candace Tan, PharmD

University of Hawaii at Hilo

The Daniel K. Inouye College of Pharmacy

Address: 677 Ala Moana Blvd. \#1025, Honolulu, HI 96813

Telephone: 626-833-2258

E-mail: candacet@usc.edu

Deborah T. Juarez, ScD

University of Hawaii at Hilo

The Daniel K. Inouye College of Pharmacy

Stacy Haumea, MPH

Bay Clinic Inc.

Charlotte Grimm, APRN

Bay Clinic Inc.

* corresponding author 